\title{
Treatment of polypoidal choroidal vasculopathy with photodynamic therapy combined with intravitreal injections of ranibizumab.
}

\section{AUTHOR(S):}

Tomita, Kaoruko; Tsujikawa, Akitaka; Yamashiro, Kenji; Ooto, Sotaro; Tamura, Hiroshi; Otani, Atsushi; Nakayama, Yoshihito; Yoshimura, Nagahisa

\section{CITATION:}

Tomita, Kaoruko ... [et al]. Treatment of polypoidal choroidal vasculopathy with photodynamic therapy combined with intravitreal injections of ranibizumab.. American journal of ophthalmology 2012, 153(1): 68-80.e1

\section{ISSUE DATE:}

2012-01

URL:

http://hdl.handle.net/2433/152385

\section{RIGHT:}

(c) 2012 Elsevier Inc.; この論文は出版社版でありません。引用の際には 出版社版をご確認ご利用ください。; This is not the published version. Please cite only the published version. 


\section{Elsevier Editorial System(tm) for American Journal of Ophthalmology} Manuscript Draft

Manuscript Number: AJ0-11-337R1

Title: Treatment of Polypoidal Choroidal Vasculopathy with Photodynamic Therapy Combined with Intravitreal Injections of Ranibizumab

Article Type: Original Article

Keywords: age-related macular degeneration; polypoidal choroidal vasculopathy; photodynamic therapy; ranibizumab.

Corresponding Author: Dr. Akitaka Tsujikawa, MD

Corresponding Author's Institution: Kyoto University Graduate School of Medicine

First Author: KAORUKO TOMITA, MD

Order of Authors: KAORUKO TOMITA, MD; Akitaka Tsujikawa, MD; KENJI YAMASHIRO, MD; SOTARO

OOTO, MD; HIROSHI TAMURA, MD; ATSUSHI OTANI, MD; YOSHIHITO NAKAYAMA, MD; NAGAHISA YOSHIMURA, MD 


\section{ABSTRACT}

PURPOSE: To evaluate the one-year efficacy and safety of photodynamic therapy (PDT) combined with intravitreal injections of ranibizumab for polypoidal choroidal vasculopathy (PCV).

DESIGN: Retrospective chart review.

METHODS: We retrospectively reviewed the medical records of 63 consecutive patients (66 eyes) with subfoveal PCV who were treated with PDT combined with intravitreal injections of ranibizumab. Of the 66 eyes, 29 had no history of treatment for PCV, 10 had been treated previously with only intravitreal injections of anti-vascular endothelial growth factor (VEGF) agents, and 27 had been treated previously with PDT. All eyes had a minimal follow-up of 12 months.

RESULTS: The combined therapy reduced substantially the exudative change immediately after initiation of treatment. In treatment-naïve eyes, mean VA before treatment $(0.47 \pm 0.37$ in logMAR $)$ improved to $0.32 \pm 0.30(P<.01)$ at three months and to $0.29 \pm 0.29(P<.01)$ at 12 months. Polypoidal lesions were reduced in all eyes and disappeared completely in $79.1 \%$ of cases. In eyes treated previously with only anti-VEGF therapy, some visual improvement was achieved, but in eyes treated previously with PDT, mean VA $(0.61 \pm 0.45)$ deteriorated to $0.68 \pm 0.52$ at 12 months. 
Of all 66 eyes, 5 showed extensive postoperative subretinal hemorrhage, 2 of which developed a vitreous hemorrhage and underwent pars plana vitrectomy.

CONCLUSIONS: PDT combined with ranibizumab led to significant visual recovery in treatment-naïve eyes with PCV, but not in eyes with PCV that had recurred after previous PDT. PDT in combination with ranibizumab still has a risk of the postoperative hemorrhagic complications. 
Treatment of Polypoidal Choroidal Vasculopathy with Photodynamic Therapy

Combined with Intravitreal Injections of Ranibizumab

KAORUKO TOMITA, AKITAKA TSUJIKAWA, KENJI YAMASHIRO, SOTARO OOTO, HIROSHI TAMURA, ATSUSHI OTANI, YOSHIHITO NAKAYAMA, AND NAGAHISA YOSHIMURA

Short title: Photodynamic Therapy with Ranibizumab

From the Department of Ophthalmology and Visual Sciences, Kyoto University Graduate School of Medicine, Kyoto, Japan (AT, KY, SO, HT, AO, NY); Nakano Eye Clinic, Kyoto, Japan (KT, YN).

Correspondence to Akitaka Tsujikawa, MD, Department of Ophthalmology and Visual Sciences, Kyoto University Graduate School of Medicine, Sakyo-ku, Kyoto 606-8507, Japan; fax: +81-75-752-0933; e-mail: tujikawa@kuhp.kyoto-u.ac.jp 
Today, intravitreal injections of anti-vascular endothelial growth factor (VEGF) agents are a standard treatment for exudative age-related macular degeneration (AMD). ${ }^{1,2}$ As a unique form of choroidal neovascularization (CNV), ${ }^{3-5}$ polypoidal choroidal vasculopathy (PCV) is characterized by a branching vascular network that terminates in polypoidal lesions. ${ }^{6-9}$ Similar to $A M D,{ }^{10}$ recent findings of high concentrations of VEGF in aqueous humor $^{11}$ and high expression of VEGF in histologic specimens of $\mathrm{PCV}^{12}$ have suggested that VFGF is involved also in the pathogenesis of PCV. In contrast to AMD, however, it has been reported that the treatment effects of anti-VEGF agents on the vascular lesions associated with PCV are limited. ${ }^{13-24}$ In a recent report of PCV by Hikichi and associates, ${ }^{25}$ although exudative changes regressed with three monthly injections of ranibizumab, with concomitant improvement of visual acuity (VA), complete disappearance of the polypoidal lesions was achieved in only $26 \%$ of eyes.

A number of studies have shown encouraging results of photodynamic therapy (PDT) on PCV. ${ }^{26-30}$ In a report by Chan and associates, ${ }^{27}$ PDT led to complete regression of the polypoidal lesion in $95 \%$ of eyes with PCV, and resulted in stable or improved VA one year after treatment. Unfortunately, one or more years after successful treatment with PDT, some eyes have a recurrence of the PCV lesions and, consequently, a decrease in VA. ${ }^{31,32}$ Akaza and associates ${ }^{33}$ reported that $64 \%$ of eyes with PCV that had 
been successfully treated with PDT showed a recurrence of the polypoidal lesions during a follow-up of 24 months. These recurrent polypoidal lesions are often accompanied by an exudative change, which results in a poor visual prognosis in spite of retreatment using PDT. ${ }^{31-33}$

Several investigators have reported promising short-term results of PDT combined with bevacizumab for the treatment of PCV. ${ }^{34-38}$ Recently, Ruamviboonsuk and associates $^{39}$ reported one-year results of 12 eyes with PCV that were treated with PDT combined with ranibizumab. To date, however, the efficacy and safety of this combined therapy has not been sufficiently evaluated. ${ }^{37}$ In addition, most reports have involved PCV that had no previous treatments. ${ }^{23,35,36,39}$ In the clinical setting, physicians often need to treat eyes in which PCV has recurred after initial treatment with PDT or eyes with chronic PCV that is refractory to anti-VEGF agents, ${ }^{31-33}$ but, again, little information is available on the efficacy of combined therapy in such cases. ${ }^{34}$ Accordingly, the study described herein was designed to study the safety and efficacy of PDT combined with ranibizumab for the treatment of symptomatic PCV, depending on the history of previous treatment(s). 


\section{PATIENTS AND METHODS}

For this case series, we studied retrospectively the medical records of 66 consecutive

eyes (63 patients) with subfoveal PCV that were treated with PDT combined with intravitreal injections of ranibizumab (Lucentis; Novartis, Bülach, Switzerland) at Kyoto University Hospital between the beginning of May 2009 to the end of February 2011. Inclusion criteria of the study were (1) symptomatic subfoveal PCV, (2) presence of exudative or hemorrhagic features involving the macula, (3) VA of 0.7 or less on a Landolt chart before treatment, and (4) a minimum follow-up of 12 months after the initial treatment. The diagnosis of PCV was based on indocyanine green angiography, which shows a branching vascular network that terminates in polypoidal swelling. In the current study, all eyes showed a polypoidal lesion, a branching vascular network, or type 2 CNV beneath the foveal center. Eyes with other macular abnormalities (i.e., AMD, pathologic myopia, idiopathic CNV, presumed ocular histoplasmosis, angioid streaks and other secondary CNV) were excluded from the study. However, pseudophakic eyes were included, but eyes with a history of vitrectomy were excluded.

At the initial visit, each patient underwent a comprehensive ophthalmologic examination, including measurement of best-corrected VA with a Landolt chart, 
determination of intraocular pressure, indirect ophthalmoscopy, slitlamp biomicroscopy with a contact lens, spectral-domain optical coherence tomography (OCT) (Spectralis HRA+OCT, Heidelberg Engineering, Heidelberg, Germany), and fluorescein and indocyanine green angiography (HRA-2, Heidelberg Engineering). Patients who had a visual disturbance due to PCV were offered PDT combined with an intravitreal injection of $0.5 \mathrm{mg}$ ranibizumab. Injections of ranibizumab were performed in a sterile manner and prophylactic topical antibiotics were applied for 1 week after the injection. At 3-4 days after the intravitreal injection of ranibizumab, normal-fluence PDT was performed using a 689 nm diode laser unit (Visulas PDT system 690S; Carl Zeiss, Dublin, California) after an injection of verteporfin (Visudyne; Novartis), according to PDT guidelines for AMD. ${ }^{40}$ The greatest linear dimension chosen was based on fluorescein and indocyanine green angiograms, as previously described. ${ }^{28}$ All polypoidal lesions and the entire branching vascular network detected with indocyanine green angiography and type 2 CNV detected with fluorescein angiography were included. Serous pigment epithelial detachment was not included in the lesion area when the absence of underlying CNV was confirmed. After the initial treatment, each patient was scheduled for an examination at 3 months, at which time they again underwent a comprehensive ophthalmologic examination. When indocyanine green angiography showed recurrent or residual 
polypoidal lesions and when an exudative change was seen on OCT, additional combination therapy was given. When residual polypoidal lesions were detected on indocyanine green angiography but no exudative change was seen on OCT, no additional treatment was given and the patient was reevaluated at the next visit. When only recurrent or residual exudative changes due to PCV were seen by OCT examination but neither polypoidal lesions nor type 2 CNV were seen on angiography, an additional injection of ranibizumab was given. After the additional injection of ranibizumab, the patient was scheduled to visit our clinic after one month, at which time they again underwent a comprehensive ophthalmologic examination.

In the current study, we studied 66 eyes with subfoveal PCV that were treated with PDT combined with intravitreal injections of ranibizumab. Of these 66 eyes, 29 had no history of treatment for PCV (treatment-naïve group). Ten eyes had been treated previously with only intravitreal injections of anti-VEGF agents, including ranibizumab, pegaptanib (Macugen; Pfizer, New York, New York), or bevacizumab (Avastin; Genentech, South San Francisco, California); these eyes had no history of PDT treatment (anti-VEGF group). Twenty-seven eyes had been treated previously with PDT for PCV (PDT group). Of the 27 eyes in the PDT group, 18 had also been treated previously with intravitreal injections of anti-VEGF agents. 


\begin{abstract}
All values are presented as mean \pm standard deviation. For statistical analysis, best-corrected VA as measured with a Landolt chart was converted to a logarithm of the minimum angle of resolution (logMAR). VA was considered to be improved or deteriorated when the logMAR change was greater than 0.3 . On OCT sections, foveal thickness was defined as the distance between the inner surface of the neurosensory retina and the retinal pigment epithelium beneath the fovea. In each group, VA or foveal thickness after the combined therapy was analyzed by one-way repeated measures analysis of variance with the Dunnett method. At each time point, the change in VA or in foveal thickness was analyzed using the least significant difference procedure. Software (StatMate III; ATMS, Tokyo, Japan) was used for the statistical analyses. A $P$ value $<.05$ was considered to be statistically significant.
\end{abstract}




\section{RESULTS}

In the study described herein, 66 eyes of 63 patients (44 men and 19 women), ranging in age from 57 to 85 years $(72.1 \pm 8.0$ years $)$, underwent PDT combined with intravitreal injections of ranibizumab for the treatment of PCV. All patients were Japanese, and all were of Asian ancestry. Of these 66 eyes, 29 had no history of treatment for PCV (treatment-naïve group). Ten eyes had previously been treated with only intravitreal injections of anti-VEGF agents (anti-VEGF group); the mean number of previous anti-VEGF treatment was $4.30 \pm 2.83$ (range: $1-9$ ). Twenty-seven eyes had been treated previously for their PCV with PDT (PDT group); the mean number of previous PDT and anti-VEGF treatments was $1.63 \pm 0.74$ (range: $1-3$ ) and $1.67 \pm 1.03$ (range: $0-4$ ), respectively. In the study period over 12 months, the mean number of combined treatments was $1.38 \pm 0.63$ (range: $1-4$ ).

In the treatment-naïve group, all eyes showed an exudative change due to the PCV; cystoid macula edema was seen in 9 eyes (31.0\%), serous retinal detachment in 27 (93.1\%), and serosanguineous pigment epithelial detachment in 12 (41.4\%). Initial combined therapy reduced substantially the exudative change. At three months, reduced size of the cystoid space and a serous retinal detachment was seen in only 5 eyes and 6 
eyes, respectively. Of the 12 eyes with a serosanguineous pigment epithelial detachment, 10 showed a reduction of its size and 5 showed complete resolution at three months. Of 24 eyes examined at three months with indocyanine green angiography, the polypoidal lesion was reduced in size in all eyes and had disappeared completely in 19 eyes (79.1\%) (Figures 1 and 2). However, a branching vascular network remained in all eyes. Figure 3 shows the change in VA and in foveal thickness after treatment of the treatment-naïve group. Combined therapy reduced substantially the exudative change immediately after initiation of treatment. The foveal thickness was reduced significantly from $390.3 \pm 143.2 \mu \mathrm{m}$ before treatment to $252.9 \pm 104.3 \mu \mathrm{m}(P<.01)$ at three months, and to $227.4 \pm 50.3 \mu \mathrm{m}(P<.01)$ at 12 months. The mean VA before treatment $(0.47 \pm$ $0.37)$ also improved significantly, being $0.32 \pm 0.30(P<.01)$ at three months. The improvement of VA was maintained until 12 months $(0.29 \pm 0.29, P<.01)$. At 12 months, significant improvement of VA was seen in 10 eyes (34.5\%) and deterioration of VA was seen in one eye (3.5\%) (Figure 4). Over this 12-month period, additional combined therapy to residual polypoidal lesions with an exudative change was performed in 9 eyes (31.0\%). If only an exudative change remained, additional ranibizumab injections were given (7 eyes; $24.1 \%$ ). In the treatment-naïve group, although two eyes showed subretinal hemorrhage (larger than 4 disc areas) after the combined therapy, the 
hemorrhage was absorbed spontaneously with no decrease in VA (Figure 5). During this 12-month period, no other serious adverse event was seen in the treatment-naïve group. In the anti-VEGF group, combined therapy reduced substantially the exudative change. The mean foveal thickness was reduced significantly from $434.8 \pm 243.2 \mu \mathrm{m}$ before treatment to $276.1 \pm 148.9 \mu \mathrm{m}(P<.05)$ at three months, and to $311.4 \pm 166.7 \mu \mathrm{m}$ $(P<.05)$ at 12 months. The mean VA was improved from $0.51 \pm 0.36$ before treatment to $0.39 \pm 0.37$ at three months and to $0.40 \pm 0.46$ at 12 months, although this improvement was not statistically significant. At 12 months, significant improvement of VA was seen in three eyes (30.0\%) while significant deterioration was seen in one (10.0\%). During the first 12 months, additional combined therapy was performed in four eyes $(40.0 \%)$ and additional ranibizumab injections were given in one eye (10.0\%). During 12 months, no serious adverse event was seen in any eye of the anti-VEGF group.

In the PDT group, combined therapy reduced substantially the exudative change. The mean foveal thickness was reduced significantly from $399.3 \pm 211.8 \mu \mathrm{m}$ before treatment to $266.0 \pm 95.2 \mu \mathrm{m}(P<.01)$ at three months, and to $318.0 \pm 140.6 \mu \mathrm{m}(P<.01)$ at 12 months. With treatment, however, the mean VA did not improve throughout the follow-up period. The mean VA $(0.61 \pm 0.45$ before treatment) remained $0.61 \pm 0.46$ at three months and deteriorated somewhat to $0.68 \pm 0.52$ at 12 months (Figure 6). At 12 
months, significant improvement of VA was seen in only three eyes $(11.1 \%)$ while significant deterioration was seen in five (18.5\%). During 12 months, additional combined therapy was performed in eight eyes (29.6\%) and additional ranibizumab injections were given to in two eyes (7.4\%). In this PDT group, three eyes showed extensive subretinal hemorrhage after treatment. Of these, two developed vitreous hemorrhage and underwent pars plana vitrectomy.

Table 2 shows the change in VA and foveal thickness from pretreatment values in each group. No difference was seen in the change of foveal thickness among the three groups. In addition, no significant difference was seen in the change of VA between the treatment-naïve group and the anti-VEGF group. However, change of VA in the PDT group was significantly worse than that of the treatment-naïve group at three months and thereafter $(P<.05)$. 


\section{DISCUSSION}

Several investigators have reported the effects of anti-VEGF agents for the treatment of exudative PCV. ${ }^{13-18,21-24}$ Cheng and associates ${ }^{24}$ recently reported one-year results of intravitreal injections of bevacizumab for PCV. With a mean of 3.3 injections per affected eye over 12 months, mean VA (logMAR) improved from $0.79 \pm 0.42$ to $0.67 \pm 0.51$, although complete resolution of the polypoidal lesions was confirmed in only $16.1 \%$ of the eyes. With the use of another anti-VEGF agent, Kokame and associates ${ }^{22}$ showed that monthly injections of ranibizumab successfully reduced the exudative changes of PCV. However, even with monthly injections, reduction of the polypoidal lesion was achieved in only $33 \%$ of eyes, and the branching vascular network remained in all eyes. While anti-VEGF agents can reduce the exudative change due to PCV, often resulting in VA recovery, their effect on the reduction of the vascular lesions of PCV appears limited. ${ }^{13-24}$ In contrast, a number of studies have shown encouraging results of PDT for the vascular lesions of $\mathrm{PCV},{ }^{26-30}$ and complete regression of the polypoidal lesions is usually achieved with a small number of PDT sessions. ${ }^{26-30}$ In a report by Chan and associates, ${ }^{27}$ PDT resulted in complete regression of polypoidal lesion in 95\% of eyes with PCV. Furthermore, visual recovery after PDT is reported to be more favorable in eyes with PCV 
than in those with AMD; Gomi and associates ${ }^{29}$ have shown that the median change in VA from baseline to 1 year was -7.0 letters in AMD and +8.0 letters in PCV. However, even if all of the polypoidal lesions regress with PDT, its effect on the branching vascular network remains limited, ${ }^{28,29}$ and the remaining branching vascular network may be involved in the recurrence of polypoidal lesions one or even more years after successful treatment with PDT. ${ }^{31-33,41}$

In the combination therapy, anti-VEGF agents, which rapidly reduce the exudative change, ${ }^{13-18,21-24}$ are expected to contribute to visual recovery in cooperation with regression of the polypoidal lesions induced by PDT. $^{26-30}$ In addition, because increased expression of VEGF shortly after PDT has been reported, ${ }^{42}$ it seems logical to inject an anti-VEGF agent before PDT treatment. ${ }^{23,34-36,39}$ Recently, several investigators reported promising one-year results of PDT combined with bevacizumab for the treatment of PCV (Table 3). ${ }^{23,35,36,38}$ Using PDT in combination with bevacizumab for PCV, Sato and associates $^{35}$ reported that the mean improvement in VA was 2.69 lines, and that VA improved by 3 lines or more in $51.7 \%$ of eyes, and, using a similar combination of ranibizumab and PDT for 12 eyes with PCV, Ruamviboonsuk and associates ${ }^{39}$ achieved a gain in VA of 15 letters or more in $58.3 \%$ of eyes at 12 months.

Using PDT combined with ranibizumab in treatment-naïve PCV eyes of our patients, 
the polypoidal lesions disappeared completely in $79.1 \%$ of eyes, with a substantial reduction in exudative change. The mean change in VA was $-0.16 \pm 0.27$ at 3 months and was $-0.18 \pm 0.34$ at 12 months. Otani and associates ${ }^{28}$ previously reported one-year results of PDT alone on subfoveal PCV, with inclusion criteria quite similar to those of the current study (Table 3). In that report, ${ }^{28}$ the mean number of treatments was no different from that of the present study. However, changes in VA at 3 months $(-0.05 \pm 0.17)$ and at 12 months $(-0.11 \pm 0.30)$ were less than in the current study, although the difference was not statistically significant. Our findings are consistent with those recently reported by Gomi and associates, ${ }^{36}$ who found that PDT combined with bevacizumab for the treatment of PCV yielded better visual recovery at one year than did PDT alone. ${ }^{36}$ Thus, for the treatment of PCV, PDT in combination with anti-VEGF agents seems to have a good effect on short-term visual recovery. ${ }^{34-36,38,39}$

Recently, a randomized prospective study (EVEREST study) has shown the 6-month efficacy of PDT in combination with ranibizumab for PCV (Lai TY, et al. IOVS 2010;51:ARVO E-Abstract 2228). In that study, complete regression of polypoidal lesions was achieved at 6 months in $77.8 \%$ after combination therapy, in $71.4 \%$ after PDT alone, and in $28.6 \%$ after intravitreal injections of ranibizumab. The mean change in VA at 6 months was $+10.9,+7.5$, and +9.2 for the combination therapy, PDT, and ranibizumab 
groups, respectively; PCV eyes treated with PDT combined with ranibizumab achieved the highest gains of VA at 6 months. Our results in the treatment-naïve group are quite similar to those of the combination group in the EVEREST study. However, because the current study is retrospective, it is difficult to compare strictly our results with those of the EVEREST study.

In the study described herein, PCV that recurred after previous PDT did, indeed, show a reduction of exudative change, but this did not result in further visual recovery, an observation similarly reported by Romano and associates, ${ }^{34}$ who observed that in eyes with PCV that were refractory to treatment by PDT alone, PDT combined with bevacizumab resulted in morphologic stabilization of the PCV lesions, but not in visual recovery. ${ }^{34}$ The reason for the poor change in VA seen in the PDT group after the combined therapy is unclear, although damage of the choriocapillaris or retinal pigment epithelium due to previous PDT might be involved. Rather, recent reports have shown the association of some genetic factors to the response to PDT and to subsequent visual prognosis in eyes with PCV. ${ }^{43,44}$ Originally, PDT group might consist of the eyes that have genetically poor VA prognosis.

To date, limited information is available on combined therapy for PCV that is refractory to anti-VEGF therapy. The current study has shown that some visual recovery 
can be expected when PDT is combined with ranibizumab, even in eyes with PCV that were previously treated with anti-VEGF agents. Because the effect of anti-VEGF therapy on polypoidal lesions is limited, ${ }^{13-18,21-24}$ combined therapy may well be a treatment option when recurrent or persistent exudative change is seen after anti-VEGF treatments.

For treatment of PCV, one of the most vision-threatening complications of PDT is extensive postoperative hemorrhage. ${ }^{45,46}$ In a previous paper on PCV treated with PDT, Hirami and associates ${ }^{45}$ reported that postoperative subretinal hemorrhage was seen in $28(30.8 \%)$ of 91 eyes, and that bleeding resulted in a vitreous hemorrhage in 6 eyes. Recent reports by Gomi and associates ${ }^{36}$ and by Sato and associates ${ }^{35}$ suggested a lower incidence of subretinal hemorrhage when the PDT was combined with bevacizumab. In the current study, two eyes in the treatment-naïve group had an extensive subretinal hemorrhage (larger than 4 disc areas) after such combined therapy, although the hemorrhage was absorbed spontaneously with no decrease in VA. In addition, three eyes in the PDT group had an extensive subretinal hemorrhage after treatment, and this resulted in vitreous hemorrhage in two eyes, so it is uncertain whether or not combined therapy actually reduces the posttreatment hemorrhagic complications. However, similar to PDT alone, even if PDT is combined with anti-VEGF agents, 
physicians need to keep in mind the risk to their patients of these complications.

Major limitations of the current study are its retrospective nature, its small sample size, and its lack of control individuals. Furthermore, we used a Landolt chart, which is based on an uneven spatial gradient scale, for the measurement of VA. However, despite these shortcomings, our findings suggest that PDT combined with intravitreal injections of ranibizumab results in rapid regression of the polypoidal lesions and exudative changes, and often results in improvement of VA in eyes with treatment-naïve PCV. Patients with PCV treated with PDT combined with ranibizumab do have a risk of posttreatment hemorrhagic complications. However, because our findings are based on an observation period of only 12 months, it remains unclear whether or not PDT in combination with ranibizumab reduces the recurrence rate of $\mathrm{PCV}$. Because the long-term efficacy of PDT alone is not as promising as was thought initially, prospective long-term studies are needed to determine the efficacy and safety of combined therapy for PCV. 


\title{
ACKNOWLEDGEMENTS
}

\begin{abstract}
A. Funding/Support: This study was supported in part by the Japan Society for the Promotion of Science (JSPS), Tokyo, Japan (Grant-in-Aid for Scientific Research, no. 21592256), and the Japan National Society for the Prevention of Blindness, Tokyo, Japan.
\end{abstract}

B. Financial Disclosures: none.

C. Contributions of Authors: conception and design of the study (KT, AT, KY, SO, $\mathrm{NY}$ ); analysis and interpretation (KT, AT, KY, SO, HT, OA, YN, NY); writing of the article (KT, AT); critical revision of the article (KY, SO, HT, OA, YN, NY); final approval of the article (KT, AT, KY, SO, HT, OA, YN, NY); data collection (KT, HT, OA, YN).

D. Ethics Committee Approval: The current study was approved by the Institutional Review Board at Kyoto University Graduate School of Medicine and adhered to the tenets of the Declaration of Helsinki. For treatment, written informed consent was obtained from each patient. According to the guidelines, it is not mandatory to obtain informed consent from the patients for a retrospective study in which the researchers review only medical records.

E. Other Acknowledgments: none. 


\section{REFERENCES}

1. Rosenfeld PJ, Brown DM, Heier JS, et al. Ranibizumab for neovascular age-related macular degeneration. N Engl J Med 2006;355(14):1419-1431.

2. Brown DM, Kaiser PK, Michels M, et al. Ranibizumab versus verteporfin for neovascular age-related macular degeneration. $\mathrm{N}$ Engl $\mathrm{J}$ Med 2006;355(14):1432-1444.

3. Yannuzzi LA, Wong DW, Sforzolini BS, et al. Polypoidal choroidal vasculopathy and neovascularized age-related macular degeneration. Arch Ophthalmol 1999;117(11):1503-1510.

4. Yannuzzi LA, Ciardella A, Spaide RF, Rabb M, Freund KB, Orlock DA. The expanding clinical spectrum of idiopathic polypoidal choroidal vasculopathy. Arch Ophthalmol 1997;115(4):478-485.

5. Uyama M, Matsubara T, Fukushima I, et al. Idiopathic polypoidal choroidal vasculopathy in Japanese patients. Arch Ophthalmol 1999;117(8):1035-1042.

6. Kleiner RC, Brucker AJ, Johnston RL. The posterior uveal bleeding syndrome. Retina 1990;10(1):9-17.

7. Stern RM, Zakov ZN, Zegarra H, Gutman FA. Multiple recurrent serosanguineous retinal pigment epithelial detachments in black women. Am J Ophthalmol 
1985;100(4):560-569.

8. Yannuzzi LA, Sorenson J, Spaide RF, Lipson B. Idiopathic polypoidal choroidal vasculopathy (IPCV). Retina 1990;10(1):1-8.

9. Spaide RF, Yannuzzi LA, Slakter JS, Sorenson J, Orlach DA. Indocyanine green videoangiography of idiopathic polypoidal choroidal vasculopathy. Retina 1995;15(2):100-110.

10. Wells JA, Murthy R, Chibber R, et al. Levels of vascular endothelial growth factor are elevated in the vitreous of patients with subretinal neovascularisation. $\mathrm{Br} \mathrm{J}$ Ophthalmol 1996;80(4):363-366.

11. Tong JP, Chan WM, Liu DT, et al. Aqueous humor levels of vascular endothelial growth factor and pigment epithelium-derived factor in polypoidal choroidal vasculopathy and choroidal neovascularization. Am J Ophthalmol 2006;141(3):456-462.

12. Matsuoka M, Ogata N, Otsuji T, Nishimura T, Takahashi K, Matsumura M. Expression of pigment epithelium derived factor and vascular endothelial growth factor in choroidal neovascular membranes and polypoidal choroidal vasculopathy. Br J Ophthalmol 2004;88(6):809-815.

13. Ghajarnia M, Kurup S, Eller A. The therapeutic effects of intravitreal bevacizumab in 
a patient with recalcitrant idiopathic polypoidal choroidal vasculopathy. Semin

Ophthalmol 2007;22(2):127-131.

14. Lai TY, Chan WM, Liu DT, Luk FO, Lam DS. Intravitreal bevacizumab (Avastin) with or without photodynamic therapy for the treatment of polypoidal choroidal vasculopathy. Br J Ophthalmol 2008;92(5):661-666.

15. Gomi F, Sawa M, Sakaguchi H, et al. Efficacy of intravitreal bevacizumab for polypoidal choroidal vasculopathy. Br J Ophthalmol 2008;92(1):70-73.

16. Song JH, Byeon SH, Lee SC, Koh HJ, Kwon OW. Short-term safety and efficacy of a single intravitreal bevacizumab injection for the management of polypoidal choroidal vasculopathy. Ophthalmologica 2009;223(2):85-92.

17. Pai SA, Shetty R. Sequential therapy with intravitreal bevacizumab and photodynamic therapy for idiopathic polypoidal choroidal vasculopathy. Acta Ophthalmol 2009;87(7):806-807.

18. Lee SY, Kim JG, Joe SG, Chung H, Yoon YH. The therapeutic effects of bevacizumab in patients with polypoidal choroidal vasculopathy. Korean $\mathrm{J}$ Ophthalmol 2008;22(2):92-99.

19. Cho M, Barbazetto IA, Freund KB. Refractory neovascular age-related macular degeneration secondary to polypoidal choroidal vasculopathy. Am J Ophthalmol 
2009;148(1):70-78.

20. Stangos AN, Gandhi JS, Nair-Sahni J, Heimann H, Pournaras CJ, Harding SP.

Polypoidal choroidal vasculopathy masquerading as neovascular age-related macular degeneration refractory to ranibizumab. Am J Ophthalmol 2010;150(5):666-673.

21. Tsujikawa A, Ooto S, Yamashiro K, Tamura H, Otani A, Yoshimura N. Treatment of polypoidal choroidal vasculopathy by intravitreal injection of bevacizumab. Jpn J Ophthalmol 2010;54(4):310-319.

22. Kokame GT, Yeung L, Lai JC. Continuous anti-VEGF treatment with ranibizumab for polypoidal choroidal vasculopathy: 6-month results. Br J Ophthalmol 2010;94(3):297-301 .

23. Rouvas AA, Papakostas TD, Ntouraki A, Douvali M, Vergados I, Ladas ID. Photodynamic therapy, ranibizumab, and ranibizumab with photodynamic therapy for the treatment of polypoidal choroidal vasculopathy. Retina 2011;31(3):464-474 .

24. Cheng $\mathrm{CK}$, Peng $\mathrm{CH}$, Chang CK, Hu CC, Chen LJ. One-year outcomes of intravitreal bevacizumab (Avastin) therapy for polypoidal choroidal vasculopathy. Retina, forthcoming.

25. Hikichi T, Ohtsuka $\mathrm{H}$, Higuchi $\mathrm{M}$, et al. Improvement of angiographic findings of 
polypoidal choroidal vasculopathy after intravitreal injection of ranibizumab monthly

for 3 months. Am J Ophthalmol 2010;150(5):674-682.

26. Spaide RF, Donsoff I, Lam DL, et al. Treatment of polypoidal choroidal vasculopathy with photodynamic therapy. Retina 2002;22(5):529-535.

27. Chan WM, Lam DS, Lai TY, et al. Photodynamic therapy with verteporfin for symptomatic polypoidal choroidal vasculopathy: one-year results of a prospective case series. Ophthalmology 2004;111(8):1576-1584.

28. Otani A, Sasahara M, Yodoi Y, et al. Indocyanine green angiography: guided photodynamic therapy for polypoidal choroidal vasculopathy. Am J Ophthalmol $2007 ; 144(1): 7-14$.

29. Gomi F, Ohji M, Sayanagi K, et al. One-year outcomes of photodynamic therapy in age-related macular degeneration and polypoidal choroidal vasculopathy in Japanese patients. Ophthalmology 2008;115(1):141-146.

30. Silva RM, Figueira J, Cachulo ML, Duarte L, Faria de Abreu JR, Cunha-Vaz JG. Polypoidal choroidal vasculopathy and photodynamic therapy with verteporfin. Graefes Arch Clin Exp Ophthalmol 2005;243(10):973-979.

31. Kurashige $Y$, Otani A, Sasahara M, et al. Two-year results of photodynamic therapy for polypoidal choroidal vasculopathy. Am J Ophthalmol 2008;146(4):513-519. 
32. Tsuchiya D, Yamamoto T, Kawasaki R, Yamashita H. Two-year visual outcomes after photodynamic therapy in age-related macular degeneration patients with or without polypoidal choroidal vasculopathy lesions. Retina 2009;29(7):960-965.

33. Akaza E, Mori R, Yuzawa M. Long-term results of photodynamic therapy of polypoidal choroidal vasculopathy. Retina 2008;28(5):717-722.

34. Romano MR, Cipollone U, Semeraro F, Rinaldi M, Costagliola C. Combined photodynamic therapy and intravitreal bevacizumab for idiopathic polypoidal choroidal vasculopathy: one-year follow-up. Clin Ophthalmol 2010;4:1237-1241.

35. Sato T, Kishi S, Matsumoto H, Mukai R. Combined photodynamic therapy with verteporfin and intravitreal bevacizumab for polypoidal choroidal vasculopathy. Am J Ophthalmol 2010;149(6):947-954.

36. Gomi F, Sawa M, Wakabayashi T, Sasamoto Y, Suzuki M, Tsujikawa M. Efficacy of intravitreal bevacizumab combined with photodynamic therapy for polypoidal choroidal vasculopathy. Am J Ophthalmol 2010;150(1):48-54.

37. Zuo C, Wen F, Li J, Liu Y, Li M. Transitions of multifocal electroretinography following combined intravitreal bevacizumab and photodynamic therapy for polypoidal choroidal vasculopathy. Doc Ophthalmol 2009;119(1):29-36.

38. Moon SW, Kim MS, Kim ES, Yu SY, Kwak HW. Photodynamic therapy combined 
with intravitreal injection of vascular endothelial growth factor antibody for polypoidal choroidal vasculopathy. Ophthalmologica $2011 ; 225(3): 169-175$.

39. Ruamviboonsuk P, Tadarati M, Vanichvaranont S, Hanutsaha P, Pokawattana N.

Photodynamic therapy combined with ranibizumab for polypoidal choroidal vasculopathy: results of a 1-year preliminary study. Br J Ophthalmol 2010;94(8):1045-1051.

40. Guidelines for using verteporfin (Visudyne) in photodynamic therapy for choroidal neovascularization due to age-related macular degeneration and other causes: update. Retina 2005;25(2):119-134.

41. Yamashiro K, Tsujikawa A, Nishida A, Mandai M, Kurimoto Y. Recurrence of polypoidal choroidal vasculopathy after photodynamic therapy. Jpn J Ophthalmol 2008;52(6):457-462.

42. Schmidt-Erfurth U, Schlötzer-Schrehard U, Cursiefen C, Michels S, Beckendorf A, Naumann GO. Influence of photodynamic therapy on expression of vascular endothelial growth factor (VEGF), VEGF receptor 3, and pigment epithelium-derived factor. Invest Ophthalmol Vis Sci 2003;44(10):4473-4480.

43. Sakurada Y, Kubota T, Imasawa M, Mabuchi F, Tanabe N, lijima H. Association of LOC387715 A69S genotype with visual prognosis after photodynamic therapy for 
polypoidal choroidal vasculopathy. Retina 2010;30(10):1616-1621.

44. Nakata I, Yamashiro K, Yamada R, et al. Genetic variants in pigment epithelium-derived factor influence response of polypoidal choroidal vasculopathy to photodynamic therapy. Ophthalmology, forthcoming.

45. Hirami $Y$, Tsujikawa A, Otani A, et al. Hemorrhagic complications after photodynamic therapy for polypoidal choroidal vasculopathy. Retina 2007;27(3):335-341.

46. Ojima Y, Tsujikawa A, Otani A, Hirami Y, Aikawa H, Yoshimura N. Recurrent bleeding after photodynamic therapy in polypoidal choroidal vasculopathy. Am $\mathrm{J}$ Ophthalmol 2006;141(5):958-960. 


\section{Figure captions}

Figure 1. Treatment-naïve polypoidal choroidal vasculopathy. (Top left) Fundus photograph shows multiple serosanguineous pigment epithelial detachments with surrounding subretinal hemorrhage. Visual acuity of the left eye was 0.03 . (Top middle) Fluorescein angiography reveals occult choroidal neovascularization (CNV). (Top right) Indocyanine green angiography (IA) shows polypoidal lesions that appear similar to a cluster of grapes (yellow arrow). (2nd row) A section of optical coherence tomography along white arrow shown in IA picture reveals a protrusion of retinal pigment epithelium due to polypoidal lesions (yellow arrow). Left eye was treated with photodynamic therapy combined with an intravitreal injection of ranibizumab. (3rd row, left) Three months after the initial treatment, subretinal hemorrhage has been absorbed and visual acuity of the left eye has improved to 0.3. (3rd row, middle) Fluorescein angiography shows atrophy of the retinal pigment epithelium. (3rd row, right) IA shows no polypoidal lesions. (Bottom) A section of optical coherence tomography along white arrow shown in IA reveals minimal exudative change with smaller pigment epithelial detachments. Visual acuity at 12 months was 0.4 in the left eye. 
Figure 2. Treatment-naïve polypoidal choroidal vasculopathy. (Top left) Fundus photograph at the initial visit shows subfoveal exudates and hemorrhage. Visual acuity of the left eye was 0.4. (Top middle) Fluorescein angiography (FA) reveals subfoveal classic choroidal neovascularization. (Top right) Indocyanine green angiography shows a branching vascular network that terminates in polypoidal lesions (arrows). (2nd row) A section of optical coherence tomography along white arrow shown on FA reveals a protrusion of retinal pigment epithelium due to polypoidal lesions (arrow) and overlying fibrin exudate. Left eye was treated with photodynamic therapy combined with an intravitreal injection of ranibizumab. (3rd row, left) Three months after treatment, the subretinal hemorrhage and exudates have been absorbed and visual acuity of the left eye has improved to 0.8 . (3rd row, middle) FA shows no classic choroidal neovascularization. (3rd row, right) Indocyanine green angiography shows no polypoidal lesions. (Bottom) A section of optical coherence tomography along white arrow shown on FA shows only reduced protrusion of the retinal pigment epithelium. Visual acuity at 12 months was 0.9 .

Figure 3. Mean foveal thickness (top) and mean visual acuity in logMAR fashion (bottom) in eyes with polypoidal choroidal vasculopathy treated with photodynamic therapy (PDT) 
combined with intravitreal injections of ranibizumab. ${ }^{*} P<.01,{ }^{\dagger} P<.05$, compared with pretreatment values. VEGF = vascular endothelial growth factor.

Figure 4. Improvement and deterioration of visual acuity at 12 months after photodynamic therapy (PDT) combined with an intravitreal injection of ranibizumab for the treatment of polypoidal choroidal vasculopathy. Visual acuity was considered to be improved or deteriorated when the change in logMAR units was greater than 0.3. VEGF $=$ vascular endothelial growth factor.

Figure 5. Extensive subretinal hemorrhage seen in polypoidal choroidal vasculopathy after photodynamic therapy combined with intravitreal injections of ranibizumab. (Top left) Treatment-naïve polypoidal choroidal vasculopathy before treatment (0.5 OD). (Top middle) One month after combined therapy, the subretinal hemorrhage has increased (0.6 OD). (Top right) Subretinal hemorrhage has been absorbed with no treatment. Visual acuity at 12 months was 0.7 OD. (Middle left) Treatment-naïve polypoidal choroidal vasculopathy before treatment $(0.3 \mathrm{OD})$. (Center) One month after the combined therapy, subretinal hemorrhage has increased (0.3 OD). (Middle right) Subretinal hemorrhage has been absorbed with no treatment. Visual acuity at 12 months 
was 0.5 OS. (Bottom left) Polypoidal choroidal vasculopathy recurred three years after the initial photodynamic therapy (0.3 OD). (Bottom middle) Six weeks after combined therapy, extensive subretinal hemorrhage is seen (0.01 OD); this eye subsequently developed a vitreous hemorrhage. (Bottom right) After pars plana vitrectomy, a large disciform scar is seen (0.02 OS at 12 months).

Figure 6. Polypoidal choroidal vasculopathy recurred after two sessions of photodynamic therapy (PDT). (Top left) Fundus photograph shows multiple serosanguineous pigment epithelial detachments with surrounding subretinal hemorrhage. Visual acuity of the left eye was 0.05. (Top middle) Fluorescein angiography reveals occult choroidal neovascularization. (Top right) Indocyanine green angiography (IA) shows a branching vascular network that terminates in polypoidal lesions (yellow arrow). (2nd row) A section of optical coherence tomography along white arrow shown on IA reveals protrusions of the retinal pigment epithelium due to polypoidal lesions. The left eye was treated with photodynamic therapy combined with an intravitreal injection of ranibizumab. (3rd row, left) Three months after treatment, subretinal hemorrhage and exudates have been absorbed. Visual acuity of the left eye was 0.1 . (3rd row, middle) FA shows no choroidal neovascularization. (3rd row, right) IA shows no polypoidal lesions. (Bottom) A section of 
optical coherence tomography along white arrow pictured on IA shows minimal

protrusion of the retinal pigment epithelium. Visual acuity at 12 months remained at 0.1 in the left eye. 
TABLE 1. Characteristics of Polypoidal Choroidal Vasculopathy in This Study Population

\begin{tabular}{lcccc}
\hline & Total & Treatment-naïve & Anti-VEGF & $\begin{array}{c}\text { PDT } \\
\text { group }\end{array}$ \\
& & & group & 27 \\
Number of eyes & 66 & 29 & 10 & $73.5 \pm 6.3$ \\
Age (years) & $72.1 \pm 8.0$ & $70.7 \pm 9.9$ & $72.3 \pm 5.5$ & $7 / 20$ \\
Gender (women/men) & $20 / 46$ & $11 / 18$ & $2 / 8$ & $1.7 \pm 1.0$ \\
Number of previous anti-VEGF treatments & - & - & $4.3 \pm 2.8$ & $1.6 \pm 0.7$ \\
Number of previous PDT treatments & - & - & - & $0.61 \pm 0.45$ \\
Initial visual acuity (logMAR) & $0.53 \pm 0.40$ & $0.47 \pm 0.37$ & $0.51 \pm 0.36$ & $399.3 \pm 211.8$ \\
Initial total foveal thickness ( $\mu$ ) & $401.0 \pm 188.9$ & $390.3 \pm 143.2$ & $434.8 \pm 243.2$ & 6 \\
Cystoid macular edema & 20 & 9 & 3 & 22 \\
Serous retinal detachment & 57 & 27 & 8 & 14 \\
Subretinal hemorrhage & 42 & 22 & 6 & 11 \\
Pigment epithelial detachment & 30 & 12 & 7 & $4780 \pm 1301$ \\
Greatest linear dimension & $4530 \pm 1339$ & $4147 \pm 1171$ & $4968 \pm 1704$ & 2 \\
Additional anti-VEGF therapy & 10 & 7 & 1 & $0.11 \pm 0.42$ \\
$\quad$ Number of additional anti-VEGF treatments & $0.39 \pm 1.20$ & $0.69 \pm 1.65$ & $0.30 \pm 0.95$ & $(1-2)$ \\
$\quad$ (range) & $(1-7)$ & $(1-7)$ & $(1-3)$ & 8 \\
Additional combined therapy & 21 & 9 & 4 & $0.41 \pm 0.75$ \\
$\quad$ Number of additional combined therapy & $0.38 \pm 0.63$ & $0.31 \pm 0.47$ & $0.50 \pm 0.71$ & $(1-3)$ \\
$\quad$ (range) & $(1-3)$ & $(1)$ & $(1-2)$ &
\end{tabular}

VEGF = vascular endothelial growth factor; PDT = photodynamic therapy; logMAR = logarithm of the minimum angle of resolution. Treatment-naïve group consisted of eyes with no previous treatment for polypoidal choroidal vasculopathy (PCV). Anti-VEGF group consisted of eyes that were treated previously with only intravitreal injections of anti-VEGF agents for PCV with no history of PDT treatment. PDT group consisted of eyes previously treated with PDT for PCV. 
TABLE 2. Changes in Visual Acuity and Foveal Thickness after Photodynamic Therapy Combined with Intravitreal Injections of Ranibizumab for Polypoidal Choroidal Vasculopathy

\begin{tabular}{lccccc}
\hline & 2 weeks & 3 months & 6 months & 9 months & 12 months \\
\hline Change in visual acuity (logMAR) & & & & & \\
$\quad$ Total group & $-0.01 \pm 0.14$ & $-0.09 \pm 0.27$ & $-0.07 \pm 0.30$ & $-0.06 \pm 0.35$ & $-0.07 \pm 0.35$ \\
$\quad$ Treatment-naïve group & $-0.02 \pm 0.14$ & $-0.16 \pm 0.27$ & $-0.13 \pm 0.27$ & $-0.16 \pm 0.35$ & $-0.18 \pm 0.34$ \\
$\quad$ Anti-VEGF group & $-0.02 \pm 0.14$ & $-0.12 \pm 0.20$ & $-0.16 \pm 0.26$ & $0.10 \pm 0.34$ & $-0.11 \pm 0.34$ \\
$\quad$ PDT group & $0.01 \pm 0.14$ & $0.00 \pm 0.26^{*}$ & $0.03 \pm 0.33^{*}$ & $0.05 \pm 0.33^{*}$ & $0.07 \pm 0.33^{*}$ \\
& & & & & - \\
Change in foveal thickness $(\mu \mathrm{m})$ & - & $-139.0 \pm 148.3$ & $-141.7 \pm 162.1$ & - & $-125.9 \pm 189.5$ \\
$\quad$ Total group & - & $-137.4 \pm 150.4$ & $-154.1 \pm 141.2$ & - & $-171.3 \pm 150.2$ \\
$\quad$ Treatment-naïve group & - & $-158.7 \pm 154.2$ & $-139.3 \pm 154.5$ & - & $-123.4 \pm 262.4$ \\
$\quad$ Anti-VEGF group & - & $-133.4 \pm 149.2$ & $-130.1 \pm 187.4$ & - & $-81.4 \pm 190.8$ \\
PDT group & - &
\end{tabular}

LogMAR = logarithm of the minimum angle of resolution; VEGF = vascular endothelial growth factor; PDT = photodynamic therapy.

Treatment-naïve group consisted of eyes with no previous treatment for polypoidal choroidal vasculopathy (PCV). Anti-VEGF group consisted of eyes that were treated previously with only intravitreal injections of anti-VEGF agents for PCV with no history of PDT treatment. PDT group consisted of eyes previously treated with PDT for PCV.

${ }^{*} P<.05$, compared with treatment-naïve group. 
TABLE 3. Previous Reports of Photodynamic Therapy and of Combined Therapy of Treatment-Naïve Polypoidal Choroidal Vasculopathy

\begin{tabular}{|c|c|c|c|c|c|c|c|c|}
\hline & Treatment & $\begin{array}{l}\text { Number } \\
\text { of Eye }\end{array}$ & Initial VA & $\begin{array}{l}\text { Change in VA } \\
\text { at } 3 \text { month }\end{array}$ & $\begin{array}{l}\text { Change in VA } \\
\text { at } 12 \text { months }\end{array}$ & $\begin{array}{c}\text { Improvement of } \\
\text { VA } \\
\text { at } 12 \text { months }\end{array}$ & $\begin{array}{c}\text { Deterioration of } \\
\text { VA } \\
\text { at } 12 \text { months }\end{array}$ & $\begin{array}{l}\text { Number of } \\
\text { PDT } \\
\text { treatments }\end{array}$ \\
\hline $\begin{array}{l}\text { Treatment-naïve eyes in the } \\
\text { current study }\end{array}$ & $\begin{array}{c}\text { PDT+ } \\
\text { ranibizumab }\end{array}$ & 29 & $0.47 \pm 0.37$ & $-0.16 \pm 0.27$ & $-0.18 \pm 0.34$ & $34.5 \%$ & $3.4 \%$ & $1.31 \pm 0.47$ \\
\hline Otani and associates ${ }^{28}$ & PDT & 45 & $0.58 \pm 0.37$ & $-0.05 \pm 0.17$ & $-0.11 \pm 0.30$ & $31.1 \%$ & $13.3 \%$ & $1.22 \pm 0.47$ \\
\hline Gomi and associates ${ }^{36}$ & $\begin{array}{c}\text { PDT+ } \\
\text { bevacizumab }\end{array}$ & 61 & 0.48 & - & -0.12 & $23.0 \%$ & $9.8 \%$ & 1.43 \\
\hline Sato and associates ${ }^{35}$ & $\begin{array}{c}\text { PDT+ } \\
\text { bevacizumab }\end{array}$ & 29 & 0.43 & $-0.21 \pm 0.27$ & $-0.27 \pm 0.34$ & $51.7 \%$ & $3.4 \%$ & 1.59 \\
\hline Moon and associates ${ }^{38}$ & $\begin{array}{c}\text { PDT+ } \\
\text { bevacizumab } \\
\text { or } \\
\text { ranibizumab }\end{array}$ & 22 & 0.43 & -0.07 & -0.15 & $36.4 \%$ & $9.1 \%$ & 1.32 \\
\hline Ruamviboonsuk and associates ${ }^{39}$ & $\begin{array}{c}\text { PDT+ } \\
\text { ranibizumab }\end{array}$ & 12 & 0.725 & $\begin{array}{l}10.8 \text { letters } \\
\text { in ETDRS }\end{array}$ & $\begin{array}{l}12.3 \text { letters } \\
\text { in ETDRS }\end{array}$ & $58.3 \%$ & $8.3 \%$ & 1.9 \\
\hline Rouvas and associates ${ }^{23}$ & $\begin{array}{l}\text { PDT+ } \\
\text { ranibizumab }\end{array}$ & 9 & 0.81 & & -0.18 & $0 \%$ & - & 1.67 \\
\hline
\end{tabular}

PDT = photodynamic therapy; VA = visual acuity; ETDRS = Early Treatment Diabetic Retinopathy Study.

Visual acuity is presented as logarithm of the minimum angle of resolution, if not otherwise indicated.

Visual acuity was considered to be improved or deteriorated when the change (logMAR) was greater than 0.3. 
F:

KYOTO UNIVERSITY)Wnload high resolution image
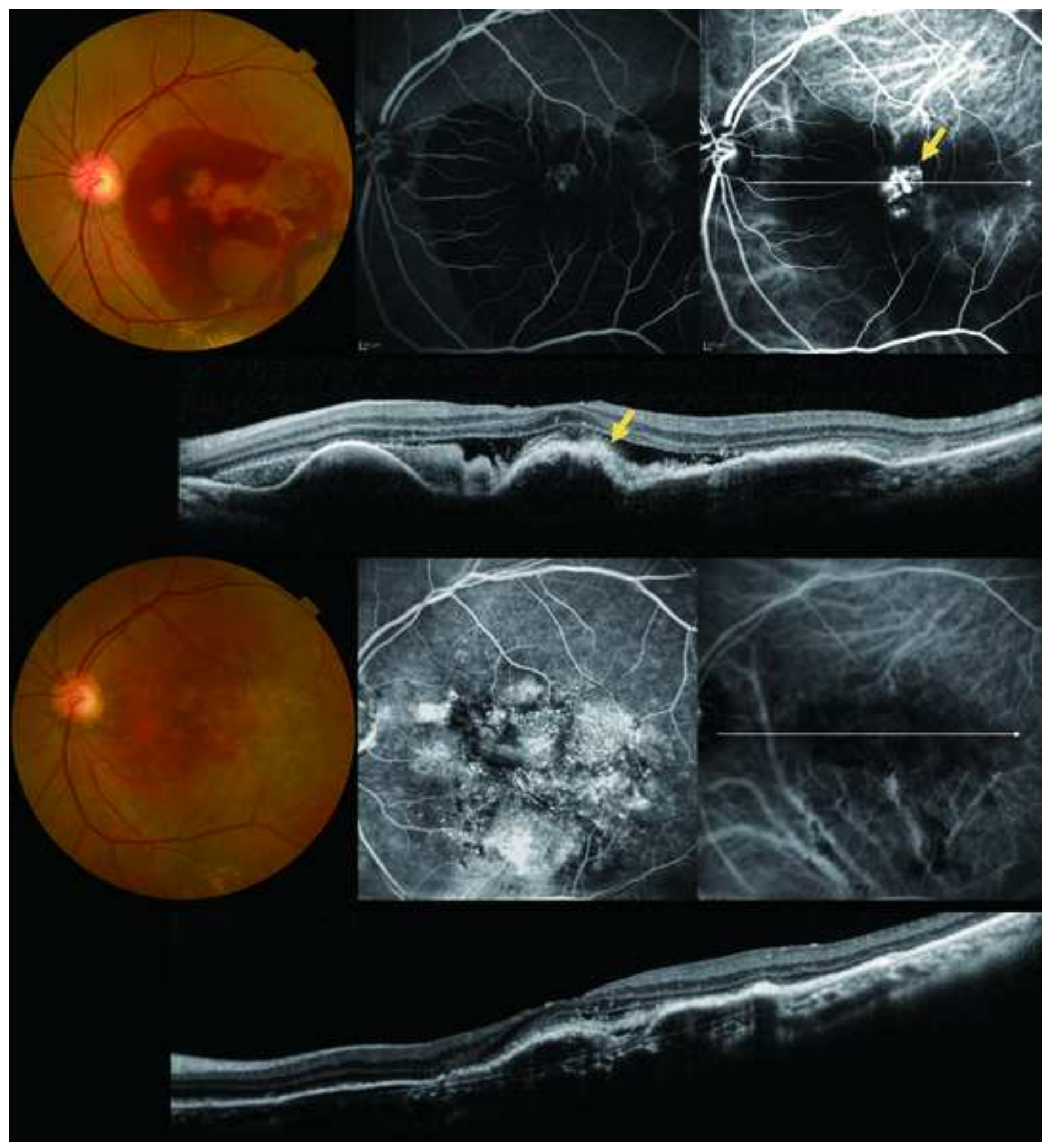


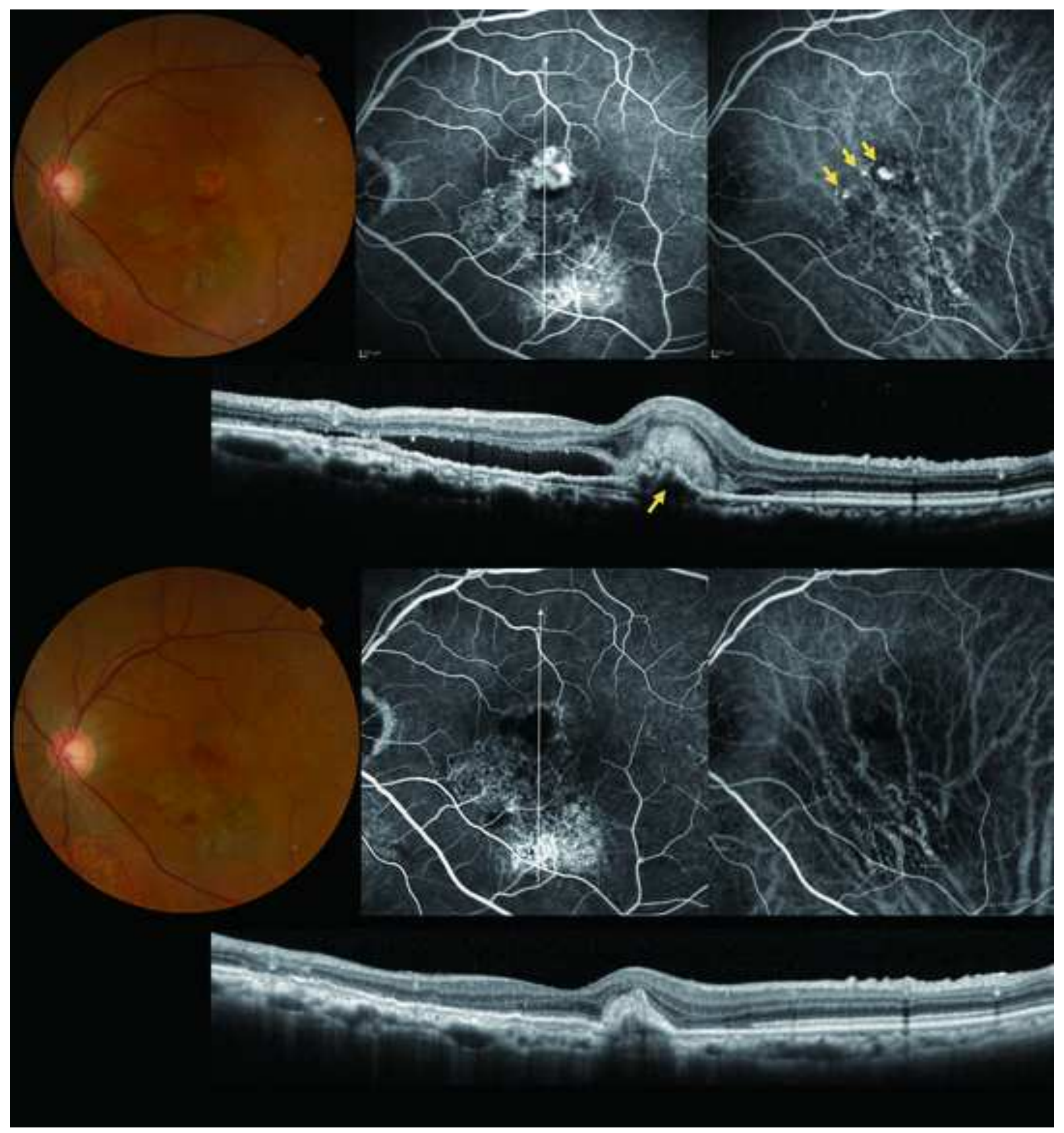



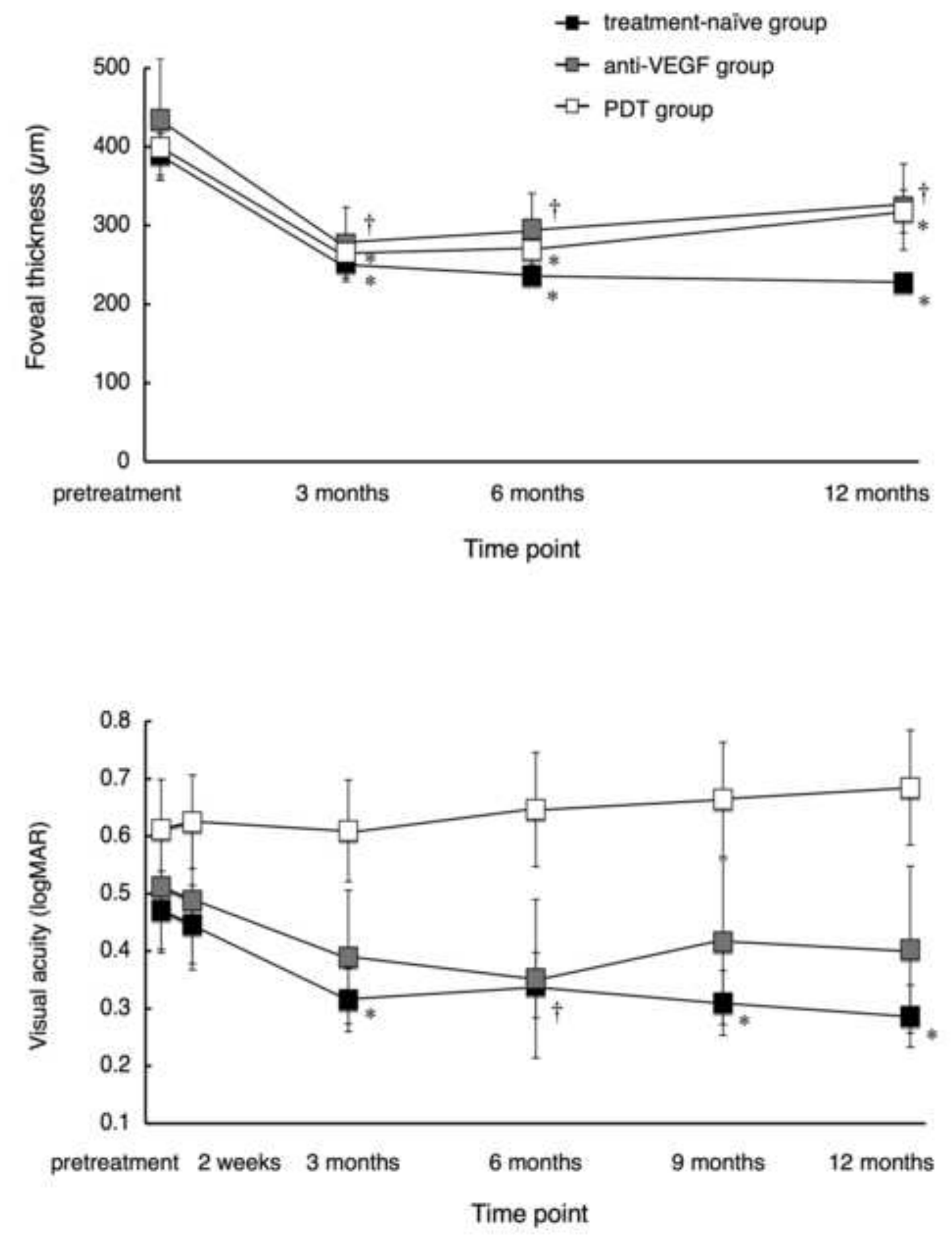

\section{Time point}

Time point

treatment-naive group

anti-VEGF group PDT group

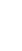

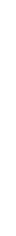

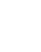


Figure 4

Click here to download high resolution image
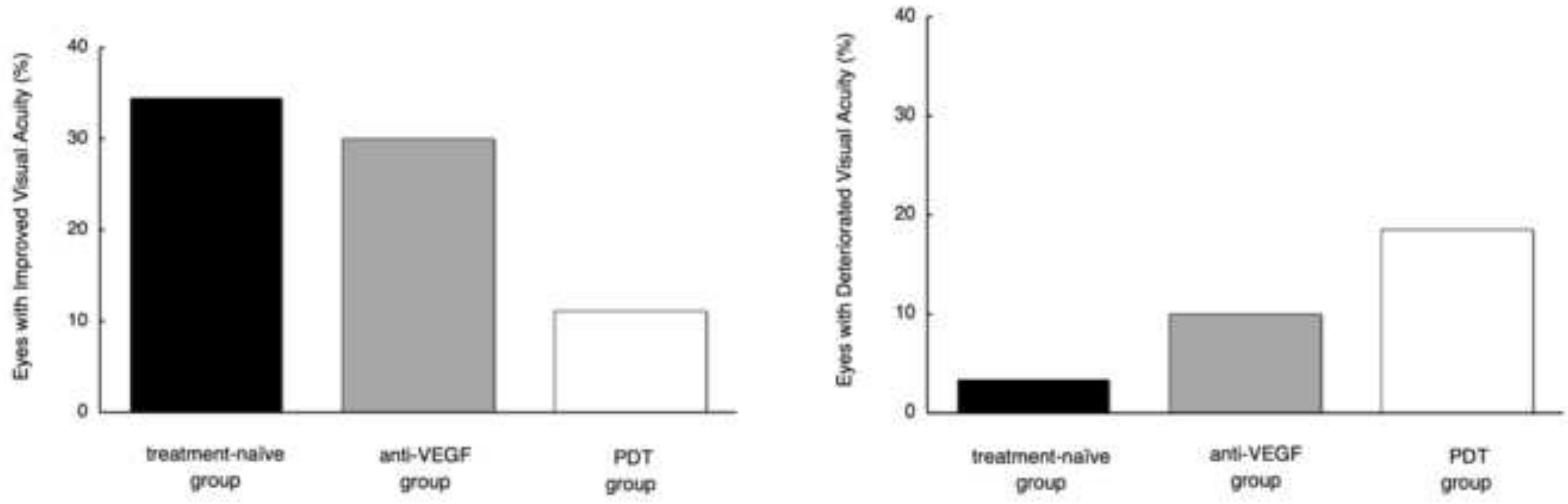


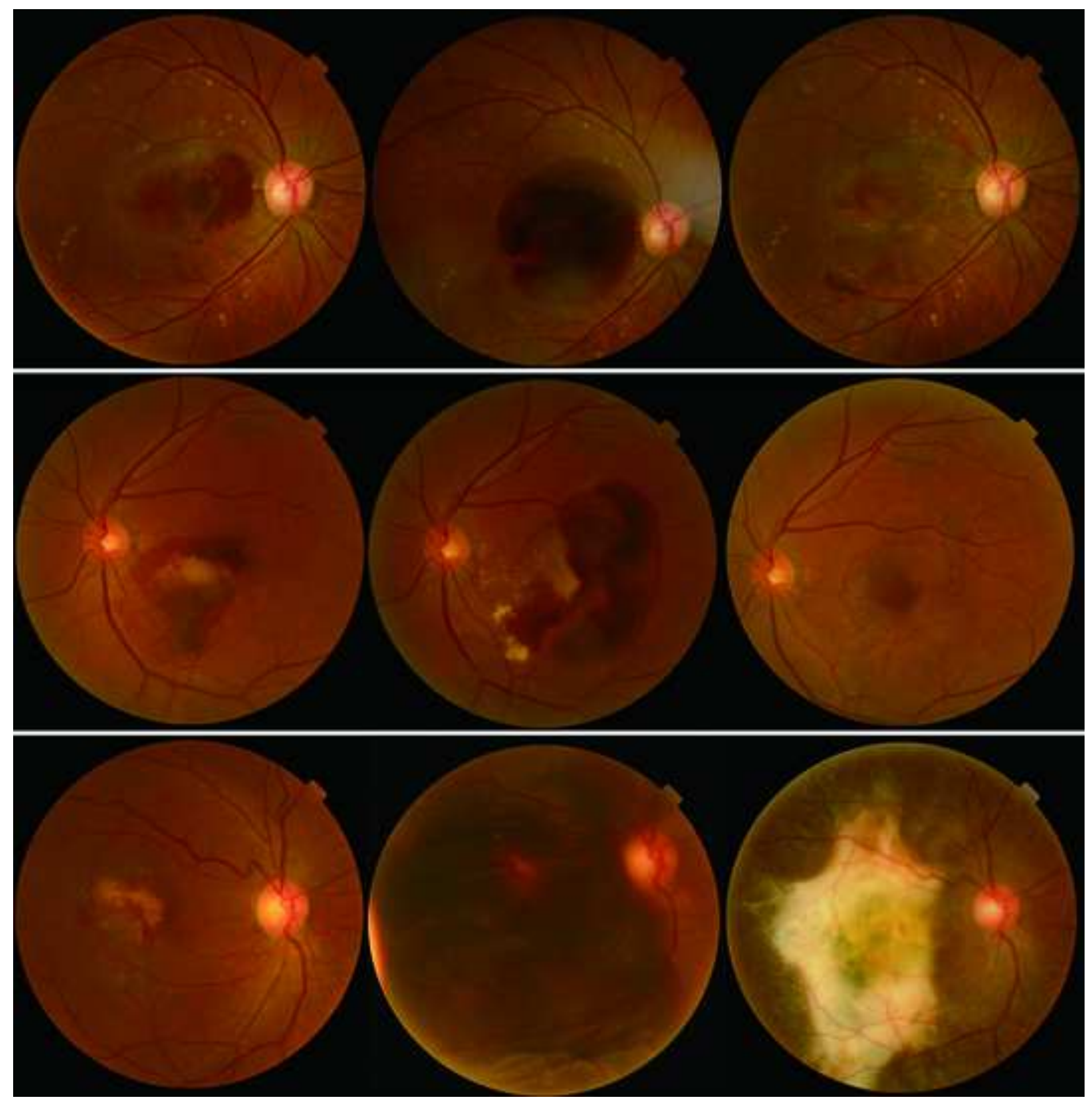




\section{Table of Contents Statement}

In eyes with polypoidal choroidal vasculopathy, photodynamic therapy combined with intravitreal injections of ranibizumab substantially diminished the polypoidal lesion and reduced the exudative change. This combined therapy led to significant visual recovery in eyes with polypoidal choroidal vasculopathy that were treatment-naive, but not in eyes with polypoidal choroidal vasculopathy that had recurred after previous photodynamic therapy. Photodynamic therapy in combination with ranibizumab does, however, still have a risk of the postoperative hemorrhagic complications. 


\section{AJO Contributions of Authors and Sponsors}

Manuscript Title: Treatment of Polypoidal Choroidal Vasculopathy with Photodynamic Therapy Combined with Intravitreal Injections of Ranibizumab

\section{Authorship Responsibility and Contributions to Authorship}

The AJO does not accept articles written by ghost writers (see J GEN INTERN MED 2005; 20:549). By submitting this manuscript, each author certifies that they have made a direct and substantial contribution to the work reported in the manuscript by participating in at least the following three areas: (1) conceiving and designing the study or analyzing and interpreting the data; (2) writing the manuscript or providing critical revisions that are important for the intellectual content; and (3) approving the final version of the manuscript. They have participated to a sufficient degree to take public responsibility for the work and believe that the manuscript describes truthful facts. They declare that they shall produce the data on which the manuscript is based for examination by the editors or their assignees, should it be requested. Each author also agrees to permit the corresponding author to make decisions regarding submission of the manuscript to the Journal, changes to galley proofs, and prepublication release of information in the manuscript to the media, federal agencies, or both.

By submitting this form, the corresponding author acknowledges that each author has read and completed 1) the statement on authorship responsibility and contribution to authorship and 2) the statement on sponsor involvement.

In the table below, please designate the substantive contribution(s) of each author. Any contribution not described in the box should be indicated in the space for "Other contributions." For a multicenter or group study, the authors listed on the title page should attest to this information but other members of the study group do not need to attest. However, they should be listed by name in an appendix. If the article is accepted, this information will appear as supplemental material at www.ajo.com.

\begin{tabular}{|c|c|c|c|c|c|c|c|c|c|c|c|}
\hline Author Name & 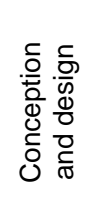 & 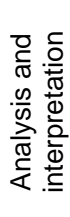 & 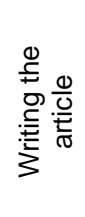 & 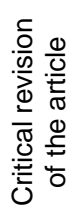 & 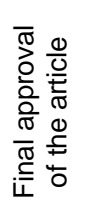 & 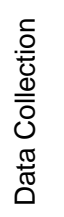 & 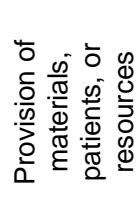 & 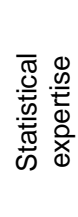 & 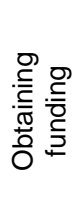 & 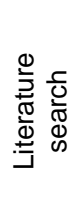 & 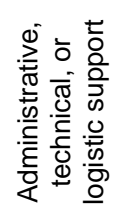 \\
\hline KAORUKO TOMITA & 凶 & 区 & 凶 & $\square$ & $\bigotimes$ & $\bigotimes$ & $\square$ & $\square$ & Х & $\bigotimes$ & $\square$ \\
\hline AKITAKA TSUJIKAWA & 凶 & 区 & 邓 & $\square$ & 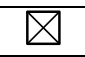 & $\square$ & $\square$ & $\square$ & $\square$ & $\bigotimes$ & $\square$ \\
\hline KENJI YAMASHIRO & 凶 & 区 & $\square$ & Х & $\bigotimes$ & $\square$ & $\square$ & $\square$ & $\square$ & $\square$ & $\square$ \\
\hline SOTARO OOTO & $\bigotimes$ & $\bigotimes$ & $\square$ & $\bigotimes$ & $\bowtie$ & $\square$ & $\square$ & $\square$ & $\square$ & $\square$ & $\square$ \\
\hline HIROSHI TAMURA & $\square$ & 区 & $\square$ & Х & 凶 & Х & $\square$ & $\square$ & $\square$ & $\square$ & $\square$ \\
\hline ATSUSHI OTANI & $\square$ & 区 & $\square$ & Х & 凶 & Х & $\square$ & $\square$ & $\square$ & $\square$ & $\square$ \\
\hline YOSHIHITO NAKAYAMA & $\square$ & $\bigotimes$ & $\square$ & $\nabla$ & $\bigotimes$ & $\bigotimes$ & $\square$ & $\square$ & $\square$ & $\square$ & $\square$ \\
\hline \multirow[t]{3}{*}{ NAGAHISA YOSHIMURA } & $\bigotimes$ & 区 & $\square$ & Х & 凶 & $\square$ & $\square$ & $\square$ & Х & $\square$ & $\square$ \\
\hline & $\square$ & $\square$ & $\square$ & $\square$ & $\square$ & $\square$ & $\square$ & $\square$ & $\square$ & $\square$ & $\square$ \\
\hline & $\square$ & $\square$ & $\square$ & $\square$ & $\square$ & $\square$ & $\square$ & $\square$ & $\square$ & $\square$ & $\square$ \\
\hline
\end{tabular}

Other contributions: 


\section{Sponsor Involvement}

Please describe in detail any involvement by a sponsor of this study in the design; collection, analysis, and interpretation of data; manuscript writing; and the decision to submit the manuscript for publication:

NONE

By submitting this manuscript, each of the authors indicate that they had full access to all of the data in this study and take complete responsibility for the integrity of the data and the accuracy of the data analysis.

As corresponding author, I certify that the above information is correct, and has been reviewed by each author.

Type your name (signature not required): AKITAKA TSUJIKAWA

Please save this file as a Word document and upload to your manuscript submission. 


\section{Biographic sketch}

Kaoruko Tomita, M.D., is a graduate of the Graduate School of Medicine of Osaka City University. She completed an ophthalmology residency at Kobe City General Hospital and a fellowship at the Osaka City University Hospital in Japan. Following the fellowship, she worked at Osaka City General Hospital, and currently works at Nakano Eye Clinic. She continues researching macular diseases at Kyoto University Graduate School of Medicine. 


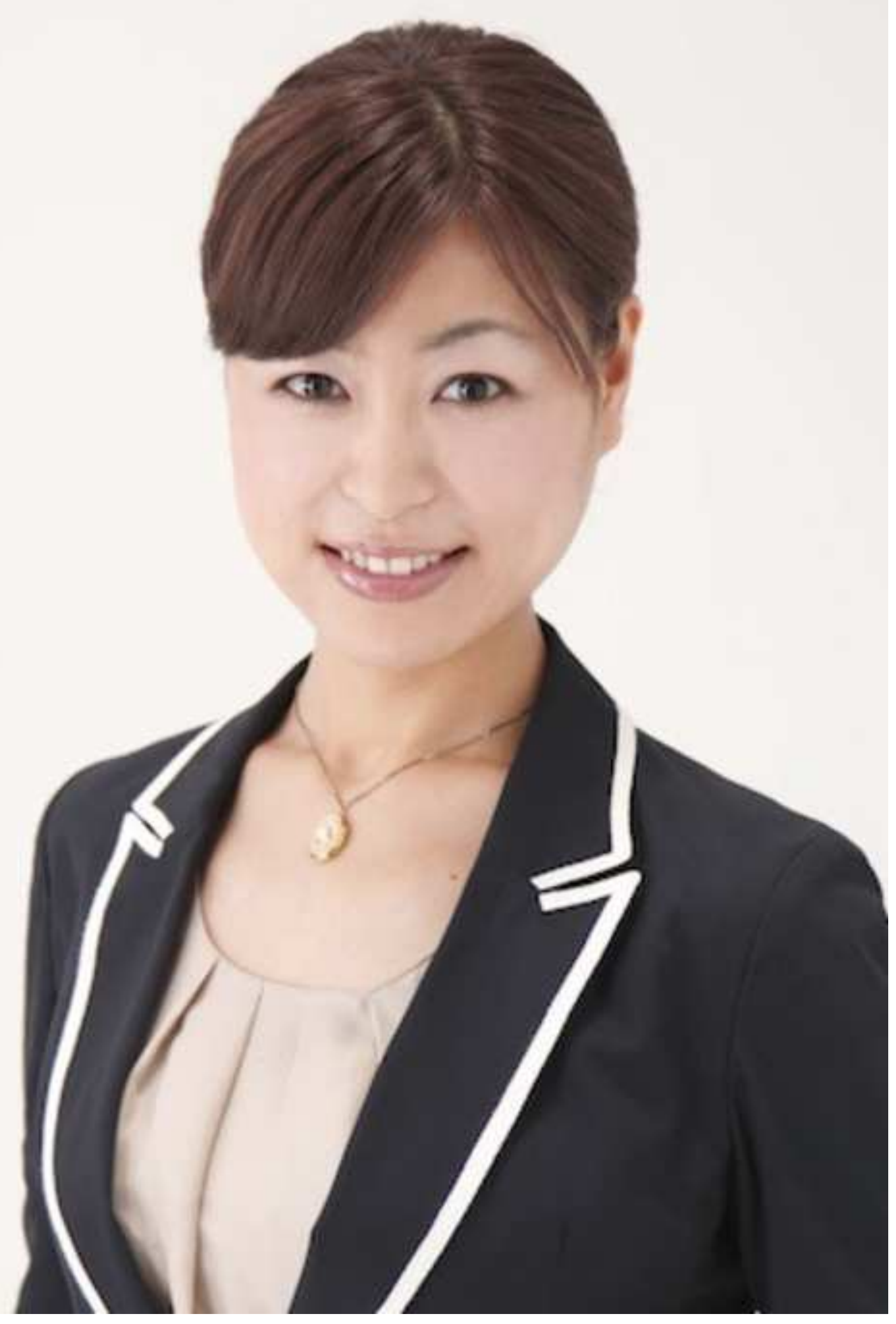

